\title{
Yüksek Gradlı Glial Tümörlerde Prognostik Faktörler ve Tedavi Sonuçlarımız: Tek Merkez Deneyimi
}

\section{Prognostic Factors and Treatment Results in High Grade Glial Tumors: Single Center Experience}

Meryem Aktan, Gül Kanyılmaz, Berrin Benli Yavuz, Mehmet Koç

Necmettin Erbakan Üniversitesi, Meram Tıp Fakültesi, Radyasyon Onkoloji Anabilim Dalı, Meram, Konya

Geliş Tarihi/Received: 19 Eylül 2017 Kabul Tarihi/Accepted: 11 Şubat 2018
Öz

Amaç: Amaç: Yüksek gradlı glial tümör tanısıyla cerrahi sonrası radyoterapi ve kemoterapi uygulanan hastaların genel özelliklerini, sağkalım sürelerini ve buna etki eden prognostik faktörleri incelemek amaçlandı.

Hastalar ve Yöntem: Dosya takip bilgileri olan 166 olgunun verileri geriye dönük olarak incelendi. Çalışmaya grad 3 Anaplastik astrositom ve grad 4 Glioblastome multiforme tanısı histopatolojik olarak doğrulanmış olgular dahil edildi. Hastalara küratif radyoterapi ve eşzamanlıt adjuvan temozolamid kemoterapisi uygulandı.

Bulgular: Hastaların \%73'ü erkek, \%27'si kadındı ve ortanca yaş 57 idi. \%21 hasta anaplastik astrositom, $\% 79$ hasta ise glioblastome multiforme tanılıydı. $\% 40$ hasta total, $\% 49$ hasta subtotal olarak opere edilmis, \%11 hastadan ise tanı amaçlı sadece biopsi alınmıştı. Radyoterapi öncesi hastaların ortanca Karnofski performans değeri 90 idi. Hastaların \%37 sine 3 boyutlu konformal radyoterapi uygulanırken $\% 63$ hasta yoğunluk ayarlı radyoterapi tekniğiyle tedavi edildi. \%92 hastaya radyoterapiyle eşzamanlı temozolamid uygulandı. Hastaların takip süresi ortanca 15 aydı. Genel sağkalım oranları anaplastik astrositom için ortanca 82 ay, glioblastome multiforme için 15.5 aydı $(p<0.001)$. 1,2 ve 5 yıllık genel sağkalım oranları anaplastik astrositom için sırasıyla $\% 77, \% 59$ ve $\% 55$, glioblastome multiforme için ise sırasıyla $\% 59, \% 33$ ve $\% 4$ bulundu. 50 yas altı hastalarda ortanca genel sağkalım 39.3 ay iken $\geq 50$ yaşda 12.4 ay bulundu $(p<0.001)$. Operasyon şekline göre genel sağkalım, total çıkarılanlarda 33.2 ay, subtotal çıkarılanlarda 13.8 ay, biopsi alınanlarda 4.9 ay bulundu $(p=0.00)$. Performansı $<70$ olanlarda genel sağkalım 8.1 ay iken, $\geq 70$ olanlarda genel sağkalım 22.3 aydı $(p=0.00)$. Üç boyutlu konformal radyoterapi uygulananlarda genel sağkalım 12.9 ay iken yoğunluk ayarlı radyoterapi uygulananlarda 21.5 aydı $(p=0.005)$. Radyoterapi dozu $<60$ Gy uygulananlarda genel sağkalım 7.8 ay iken 60 Gy verilenlerde 21.7 aydı $(p=0.00)$. Eşzamanl temozolamid kullananlarda ortanca sağkalım 18.4 ay, kullanmayanlarda ise 7.2 ay olarak bulundu $(p=0.03)$. Sonuç: Hastanın tanısı, yaşı, operasyon şekli, performansı, radyoterapi dozu, kemoterapi kullanımının sağkalım üzerine olumlu etkisi gösterilmiş olup sonuçlarımız literatür ile uyumludur.

Anahtar Kelimeler: Yüksek gradlı glial tümör; radyoterapi; prognostik faktör.

\section{Abstract}

Aim: The aim of the present study was to evaluate the general characteristics, survival time and prognostic factors affecting the high grade glial tumor after radiotherapy and chemotherapy.

Patients and Methods: Data of 166 patients were retrospectively analyzed. Included histopathologically confirmed cases were grade 3 anaplastic astrocytoma and grade 4 glioblastoma multiforme. Patients were treated with curative radiotherapy and simultaneous \pm adjuvant temozolamide.

Results: $73 \%$ of the patients were male, $27 \%$ were female and the median age was 57 years. $21 \%$ were anaplastic astrocytomas, $79 \%$ were glioblastom multiforme. $40 \%$ of the patients were total, $49 \%$ of the patients were subtotally operated and $11 \%$ of the patients had only biopsy for diagnostic purposes. The median Karnofski performance score of the patients before radiotherapy was 90. 3-dimensional conformal radiotherapy was applied to $37 \%$ of the patients, $63 \%$ of the patients were treated with intensity-adjusted radiotherapy technique. Simultaneous temozolamide was administered with $92 \%$ of patients' radiotherapy. The median follow-up time was 15 months. Overall survival rates were 82 months for anaplastic astrocytoma and 15.5 months for glioblastome multiforme $(p<0.001)$. Overall survival rates at 1,2 , and 5 years were $77 \%, 59 \%$, and $55 \%$ for anaplastic astrocytoma and $59 \%, 33 \%$, and $4 \%$ for glioblastome multiforme, respectively. Median overall survival in patients aged $<50$ years was 39.3 months, while age $\geq 50$ years was 12.4 months $(p<0.001)$. Overall survival according to operation pattern was 33.2 months in total exposures, 13.8 months in subtotal resections, and 4.9 months in biopsies $(p=0.00)$. Overall survival was 8.1 months with a performance of $<70$, while overall survival was 22.322 .3 months with $\geq 70(p=0.00)$. Overall survival was 12.9 months in patients who underwent three-dimensional conformal radiotherapy and 21.5 months in patients undergoing intensity-adjusted radiotherapy $(p=0.005)$. Overall survival was 7.8 months when applied to radiotherapy dose $<60$ Gy and 21.7 months when given 60 Gy ( $=0.00$ ). Median survival was 18.4 months and 7.2 months, respectively, using concurrent temozolamide $(p=0.03)$.

Conclusion: The diagnosis, age, type of operation, performance status, radiotherapy dose and the positive effect of chemotherapy on survival were shown and the results are consistent with the literature.

Key words: High grade glial tumor; radiotherapy; prognostic factor.
Yazıșma Adresi: Meryem Aktan, Necmettin Erbakan Universitesi, Meram Tıp Fakültesi, Radyasyon Onkoloji Anabilim Dalı, Meram, Konya

e-posta: meryemaktan@gmail.com

Atıf yapmak için: Aktan M, Kanyılmaz G, Yavuz BB, Koç M. Yüksek Gradlı Glial Tümörlerde Prognostik Faktörler Ve Tedavi Sonuçlarımız: Tek Merkez Deneyimi. Selcuk Med J 2018;34(4): 143-147
Açıklama: Yazarların hiçbiri, bu makalede bahsedilen herhangi bir ürün, aygıt veya ilaç ile ilgili maddi çıkar ilişkisine sahip değildir. Araștırma, herhangi bir dıs organizasyon tarafından desteklenmedi Yazarlar calısmanın hirincil verilerinorganizasyon tarafindan desteklenmedi. Yazarlar çalş̧anin verileri incelemesine izin vermeyi kabul etmektedirler. 


\section{GíRiş}

Gliomlar, glial hücrelerden köken alan tümörleri tanımlamak için kullanılan bir terimdir ve glial hücrelerin histolojik özelliklerine göre alt gruplara ayrılır (1). Dünya Sağlık Örgütü (DSÖ) tarafından gliomlar dört alt gruba ayrılır ve grad 3 anaplastik astrositom (AA) ve grad 4 glioblastome multiforme (GBM) yüksek gradlı glial (YGG) tümörler olarak tanımlanır ve yetişkinlerde en sık görülen santral sinir sistemi tümörleridir (2). Her yaşta görülmekle birlikte, 5. ve 6. dekattan sonra artmakta ve kadınlara oranla erkeklerde \%40 daha sık görülmektedir (3). YGG tümörlerde prognoz kötü seyretmektedir. Maksimum güvenlikli cerrahi ve radyoterapi (RT) ile eşzamanlı temozolamid (TMZ) kemoterapisine (KT) rağmen GBM' de ortalama sağkalım 14.6 aydır (4). Tüm gelişen cerrahi ve RT tekniklerine ve KT rejimlerine rağmen sağkalım süreleri 20 yıl öncesinden çok farklı değildir. Bu durum birçok araştırmacıyı, sağkalıma etki edebilecek olası faktörleri araştırmaya yönlendirmektedir.

Bu çalışmada amaç, Necmettin Erbakan Üniversitesi, Radyasyon Onkoloji Kliniği'nde radyoterapi ve eşzamanlı TMZ uygulanan YGG tümörlü hastaların genel özelliklerini, sağkalım sürelerini ve bunlara etki eden faktörleri geriye dönük olarak inceleyerek sonuçlarımızı literatürle kıyaslamaktır.

\section{HASTALAR VE YÖNTEM}

Ocak 2010- Aralık 2016 tarihleri arasında kliniğimizde yüksek gardlı glial tümör tanısı alan ve RT ile eşzamanlı temozolamid kemoterapisi uygulanan ve dosya takip bilgileri olan 166 olgunun verileri geriye dönük olarak incelendi. Çalışmaya başlamadan önce yerel etik kurul onayı alındı ve Helsinki Beyannamesinde yer alan etik prensiplere uyuldu. Çalışmaya 18 yaş üstü, DSÖ grad 3 AA ve grad 4 GBM tanısı histopatolojik olarak doğrulanmış, tanı anında uzak metastazı olmayan ve takip süresi 6 aydan uzun olan olgular dahil edildi. Total ya da subtotal olarak opere edilen ya da sadece biopsi ile tanısı konan hastalara küratif RT ve eşzamanlı KT uygulandı. Tüm hastalara RT öncesi sabitlemek amaçlı termoplastik maske yapılarak planlama tomografileri kendi kliniğimizde çekildi. Hastalara ait tanı anındaki manyetik rezonans (MR) ve bilgisayarlı tomografi (BT) görüntüleri kendi planlama sistemimize aktarıldı. Primer tümöre $2.5 \mathrm{~cm}$, ödemli alana $2 \mathrm{~cm}$ güvenlik marjı verilerek hastaların RT planları yapıldı. RT, üç boyutlu konformal RT (3BKRT) ya da yoğunluk ayarlı
RT (YART) tekniği kullanılarak uygulandı. Hastalara günlük fraksiyon başına 1.8-2 Gray (Gy) dozlarda, haftada beş gün, ortalama 30 fraksiyon RT uygulandı. Hastalara RT ile eşzamanlı $75 \mathrm{mg} / \mathrm{m}^{2} / g u ̈ n ~ v e /$ veya adjuvan $150 \mathrm{mg} / \mathrm{m}^{2} / \mathrm{gün}, 1-5$. Günler, 28 günde bir ortalama 6 kür TMZ kemoterapisi oral olarak verildi.

İzlem süreleri yaşayan olgular için tanı tarihinden son kontrol tarihine kadar geçen süre, ölen olgular için ise tanı tarihinden ölüm tarihine kadar geçen süre olarak hesaplandı. Tanı tarihinden ölüm tarihine geçen süre genel sağkalım (GS), tanı tarihinden hastalıkta nüks ya da progresyon gelişinceye kadar geçen süre progresyonsuz sağkalım (PS) olarak tanımlandı. İstatistiksel analizler SPSS (Statistical Package for Social Sciences) for Windowss 16 versiyonu ile yapıldı

Tanımlayıcı istatistikler kategorik değişkenler için olgu sayısı ve (\%) olarak, sürekli değişkenler için ortalama veya ortanca (minimum-maksimum) biçiminde ifade edildi. Kategorik değişkenlerin (yaş, cinsiyet, operasyon şekli, KPS, eş zamanlı ve/veya adjuvan temozolamid kullanılması, RT şekli ve dozu) sağkalıma etki etmesi muhtemel prognostik faktörler olarak incelendi ve genel sağkalım üzerinde istatistiksel olarak anlamlı etkilerinin olup olmadığı Log-Rank testi kullanılarak Kaplan Meier sağkalım analizi ile değerlendirildi. Bu analizde anlamlı ya da anlamlılık düzeyine yakın faktörler Cox regresyon analizi kullanılarak incelendi Risk faktörlerine ilişkin kaba sağkalım, bir-üç ve beş yıllık sağkalım süreleri hesaplandı. $p<0.05$ olan sonuçlar istatistiksel olarak anlamlı kabul edildi.

\section{BULGULAR}

Kliniğimizde yüksek gradlı glial tümör tanısı alan ve RT ile eşzamanlı temozolamid kemoterapisi uygulanan 166 hastanın 122 si (\%73) erkek, 44 ü (\%27) kadındı. Ortanca yaş 57 (18-84) idi. 33 (\%21) hastanın tanısı grad 3 (AA), 133 (\%79) hastanınki ise grad 4 (GBM) beyin tümörüydü. Tanı anında ortanca tümör boyutu $5 \mathrm{~cm}(2-9 \mathrm{~cm})$ idi. \%38 hastanın tümörü temporal bölge yarleşimliyken \%27 frontal, \%27 pariatel, \%9 ise oksipital ya da diğer bölgeler yerleşimli tümörlerdi. \%40 hastaya total kitle eksizyonu uygulanmış, \%49 hasta subtotal olarak opere edilmiş, \%11 hastadan ise tanı amaçlı sadece biopsi alınmıştı. Radyoterapi öncesi hastaların ortanca KPS değerleri 90 (40-100) idi. Hastaların \%37 sine (61 hasta) 3BKRT uygulanırken \%63 (105) hastaya YART tekniğiyle RT uygulandı. \%92 hastaya RT ile eşzamanlı TMZ KT si uygulandı. \%50 hastanın tedavi 


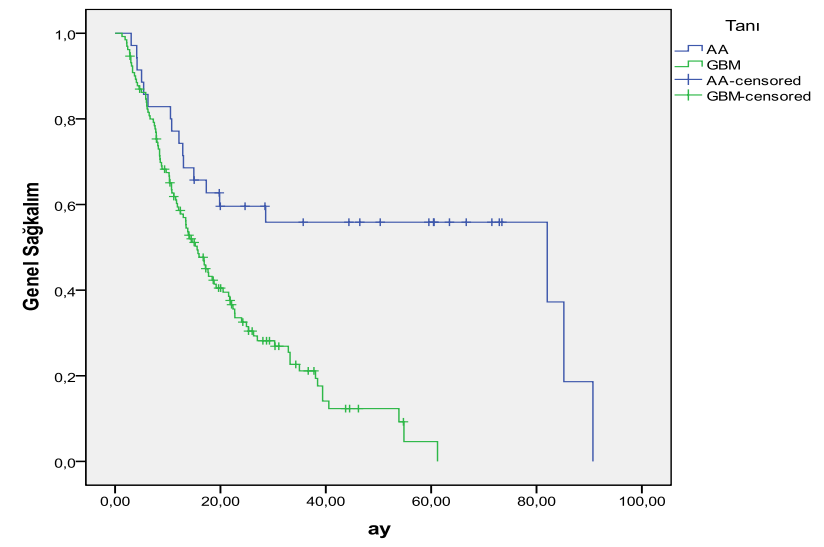

Şekil 1. Patolojik tanıya göre genel sağkalıma ait KaplanMeier eğrisi. (AA: Anaplastik Astrositom, GBM: Glioblastome Multiforme)

sırasında steroid ihiyacı olup ortalama $12 \mathrm{mg}$ steroid kullanıldı. Tedavi süresince en az haftada bir rutin kontrol edilen hastaların 9 unda grad 1 hematolojik toksisite gelişirken, 5 hastada grad 2-3, 3 hastada ise grad 4 hematolojik toksisite gelişti. Gastrointestinal (GiS) yan etkiler ise 18 hastada grad 1, 9 hastada ise gard 2 düzeyinde gelişmiş olup, garad 3-4 GiS yanetkileri ise hiçbir hastada görülmedi.

Cerrahi müdahale ile RT ye başlama arasındaki süre ortanca 31 gün (minimum 10 gün, maksimum 160 gün) olarak bulundu. Hastaların takip süresi ortanca 15 aydı (1.3 ay- 90.7 ay).

Genel sağkalım (GS) oranlarına baktığımızda AA için ortanca 82 ay, GBM için ise 15.5 aydı $(p=0.00)$

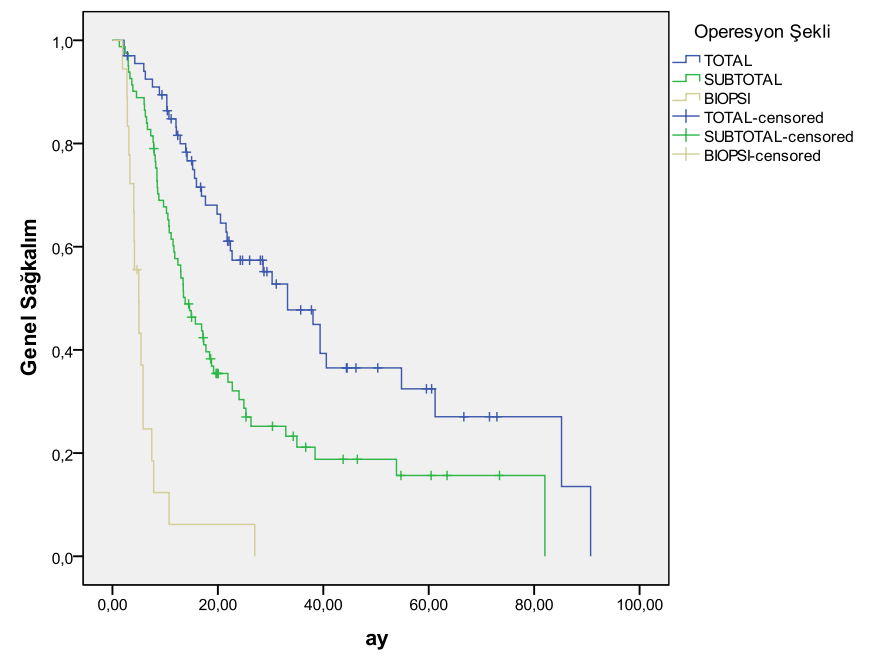

Şekil 2. Operasyon şekline göre genel sağkalıma ait Kaplan-Meier eğrisi.

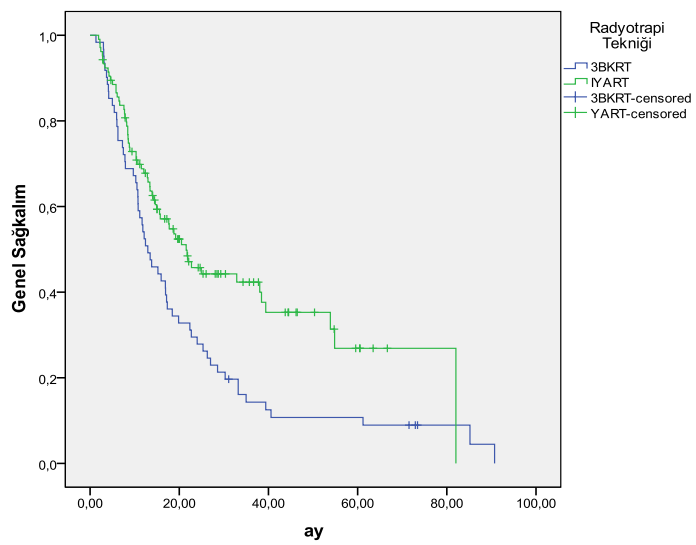

Şekil 3. Radyoterapi tekniğine göre genel sağkalıma ait Kaplan-Meier eğrisi. (3BKRT: 3 Boyutlu Konformal Radyoterapi, YART: Yoğunluk Ayarlı Radyoterapi)

(Şekil 1). 1,2 ve 5 yıllık GS oranları AA için sırasıyla $\% 77, \% 59$ ve $\% 55$, GBM için ise sırasıyla $\% 59, \% 33$ ve \%4 bulundu. Progresyonsuz sağkalım (PS), AA için ortanca 10.3 ay, GBM için ise 11.8 aydı $(p=0.07)$.

Yaşın GS ve PS üzerine olan etkisi incelendiğinde 50 yaş altındaki hastalarda ortanca GS, 39.3 ay iken 50 yaş ve üzeri hastalarda GS 12.4 ay bulundu $(p<0.001)$. Benzer şekilde 50 yaş altındaki hastalarda ortanca PS 39. ay iken 50 yaş ve üzeri hastalarda 28.4 ay olarak hesaplandı $(p=0.07)$.

Operasyon şekline göre GS süreleri hesaplandığında total olarak çıkarılanlarda 33.2 ay, subtotal çıkarılanlarda 13.8 ay iken yalnızca biopsi alınanlarda 4.9 ay olarak bulundu $(p=0.00)$ (Şekil 2). Benzer şekilde PS sürelerine bakıldığında total

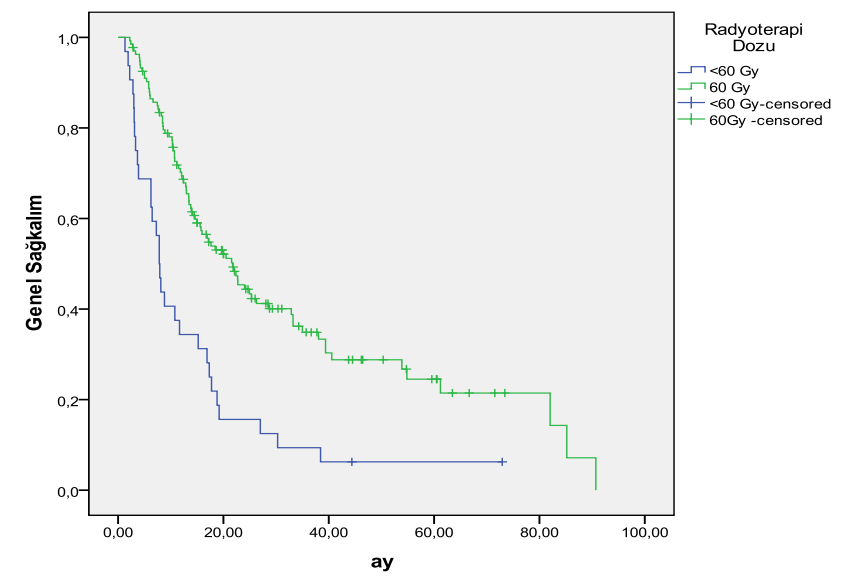

Şekil 4. Radyoterapi dozuna göre genel sağkalıma ait Kaplan-Meier eğrisi. 
olarak çıkarılanlarda 37.7 ay, subtotal çıkarılanlarda 25.3 ay iken yalnızca biopsi alınanlarda 10.7 ay olarak bulundu $(p=0.00)$. Bir, üç ve beş yıllık sağkalım oranları sırasıyla total çıkarılanlarda $\% 78, \% 44, \% 25$, subtotal çıkarılanlarda $\% 52, \% 18, \% 14$, sadece biopsi alınanlarda ise $\% 12, \% 0, \% 0$ bulundu.

RT öncesi KPS değerlerine göre GS bakıldığında KPS si 70 altında olanlarda GS 8.1 ay iken KPS si 70 ve üzeri olanlarda GS 22.3 aydı $(p=0.00)$.

RT tekniğine göre GS oranlarına bakıldığında 3BKRT uygulananlarda GS 12.9 ay iken YART uygulananlarda 21.5 aydı $(p=0.005)$ (Şekil 3). PS süreleri ise 3BKRT uygulananlarda 27 ay, YART uygulananlarda ise 38.4 aydı $(p=0.1)$.

RT dozlarına bakıldığında 60 Gy altında doz uygulananlarda GS 7.8 ay iken 60 Gy verilenlerde 21.7 aydı $(p=0.00)$ (Şekil 4). PS süreleri değerlendirildiğinde ise 60 Gy altında doz alanlarda PS 30.2 ay, 60 Gy doz alanlarda ise 33.2 aydı $(p=0.75)$.

RT ile eşzamanlı TMZ kullananlarda ortanca sağkalım 18.4 ay, kullanmayanlarda ise 7.2 ay olarak bulundu ( $p=0.03)$. PS süreleri ise kullananlarda 33.2 ay, kullanmayanlarda ise 22.7 aydı $(p=0.8)$.

\section{TARTIŞMA}

Yüksek gradlı glial tümörler erişkinlerde en sık görülen beyin tümörüdür ve standart tedavisi cerrahi, kemoradyoterapi ve adjuvan kemoterapiden oluşmaktadır. Gelişen tüm tedavi yöntemlerine rağmen genel sağkalım oranları 15 ay civarındadır $(4,5)$. Sağkalım süresinin kısa olması ve tedavi ve sonrasındaki dönemin zorlu geçmesi nedeniyle bu alanda çok çalışma yapılmıştır (6).

Curran et al. (7) yaptıkları çalışmada YGG tümörleri benzer sağkalım özelliklerine göre alt gruplara ayırmışlar (RPA: Recursive Partioning Analysis). Buna göre alt gruplar arasında sağkalım oranları 4.358.6 ay olarak belirtilmiştir. Bizim çalışmamızda da olguların \%79 u GBM tanılıydı ve GS süreleri GBM için ortanca 15.5 ay, AA için 82 ay olarak bulundu $(p<0.001)$.

Yapılan birçok çalışmada YGG tümörler için yaş, performans durumu, histolojik alttip, cerrahi rezeksiyon türü, RT dozu, eşzamanlı ve adjuvan KT kullanımı prognozu etkileyen faktörler olarak belirtilmiştir (811). Genel sağkalım ve progresyonsuz sağkalımın birincil sonlanım noktası olduğu çalışmamızda da genç yaş ( $<50$ vs $\geq 50$ yaş), yüksek KPS skoru ( $<70$ vs $\geq 70$ ), yüksek RT dozu (<60 Gy vs 60 Gy), cerrahi tipi (total/ subtotal çıkartma vs biopsi), eşzamanlı KT kullanımı genel sağkalıma olumlu etki eden faktörler olarak bulundu.

Gelişen cerrahi teknikler sayesinde daha agresif ve güvenli cerrahi yapılabilmekle birlikte tümörün tamamen çıkarılması her zaman mümkün olamamaktadır. Daha geniş rezeksiyonların prognoza olumlu katkısını gösteren yayınlar olmakla birlikte sağkalımı arttrdığına yönelik birinci derecede kanıt yoktur (12-13). Bizim hasta grubumuzda geniş rezeksiyonların genel sağkalıma katkısı olduğu gözlenmiş olup total çıkarılanlarda ortanca 33.2 ay, subtotal çıkarılanlarda 13.8 ay, sadece biopsi alınanlarda ise 4.9 ay olarak bulunmuştur $(p<0.001)$. Bir, üç ve beş yıllık sağkalımlar ise sırasıyla total çıkarılanlarda $\% 78, \% 44, \% 25$, subtotal çıkarılanlarda $\% 52, \% 18, \% 14$, sadece biopsi alınanlarda ise $\% 12$, $\% 0, \% 0$ dır ve bulgularımız literatür ile uyumluluk göstermektedir (14).

Yüksek gradlı glial tümörlerin tedavisinde cerrahi sonrası RT otuz yılı aşkın süredir kullanılmaktadır (15). Gelişen teknolojiyle birlikte RT uygulamalarıda değişmiş olup son dönemde 3 boyutlu konformal RT den (3BKRT) yoğunluk ayarlı RT (YART) gibi daha yüksek konformalite içeren ve normal dokuları daha iyi koruyan RT tekniklerine geçilmiştir. Bizim çalışmamızda \%37 hasta 3BKRT tekniğiyle RT alırken \%63 hastaya YART tekniği uygulanmıştır ve ortanca sağkalım 3BKRT uygulananlarda 12.9 ay iken YART uygulananlarda 21.5 ay bulunmuştur $(p=0.005)$.

Temozolamid imidazo-tetrazin alkilleyici etkiye sahip antitümör bir ajandır. DNA' yı alkilleyebilme özelliği sayesinde sitotoksik etkiye sahiptir.

Stupp et al. $(4,5)$ EORTC-NCIC faz 3 çalışmasında patolojik olarak GBM tanısı konulmuş 573 hastayı cerrahi sonrası 2 kola ayırmışlar, ilk gruba sadece $R T$, 2. Gruba ise RT ile eşzamanlı TMZ KT si uygulamışlardır. Bu çalışmanın 2 yıllık sonuçlarında ortanca sakalım RT kolunda 12 ay, RT + TMZ kolunda 14.6 ay olarak belirtilmiş ve 5 yıllık sonuçlarında da RT ye KT eklemenin sağkalıma olan katkısı artarak devam etmiştir. Bu çalışmadaki hastalar homojen bir grup olup performansı iyi/ orta, tümörü iyi çıkarılmış, ileri yaşlı hastaları içermeyen GBM hastalarından oluşmaktaydı. Bizim çalışmamızdaki hastalarımız ise heterojen bir grup olup ileri yaş hastalarda dahil edilmişti. Bizim çalışmamızda \%92 hastada da eşzamanlı TMZ kullanılmış olup ortanca sağkalıma katkısı istatistiksel olarak anlamlı bulundu $(p=0.03)$. İleri yaş (>60 yaş) hastaların dahil edildiği Nordic grubunun çalışmasında ise hastalar 3 ayrı kola yarıldı; tek başına $T M Z$ alan grup, hipofraksiyone RT alan grup ve standart RT alan grup. Sağkalım oranlarına 
bakıldığında özellikle 70 yaş üstü hastalarda hipofraksiyone RT ve TMZ alan grupta sağkalım oranları daha iyi bulundu (16). Bizim çalışmamızda ise 50 yaşa göre sağkalım oranlarına bakıldığında ortanca sağkalım 50 yaş altı hastalarda istatistiksel olarak anlamlı bulundu $(p<0.001)$.

Yüksek gradlı glial tümörlerde tüm tedavi yöntemlerine rağmen prognozun kötü gitmesi ve sağkalım sürelerinin kısa olması nedeniyle yeni tedavi seçenekleri araştırılmaktadır. GBM tanılı hastalarda operasyon sonrası kaviteye KT yerleştirilmesi uygulanmaktadır. Bu yöntemle operasyon sırasında tümör kavitesine Gliadel(BCNU polimerleri, Karmustin) yerleştirilerek sistemik kemotoksisiteden kaçınarak lokal KT yoğunluğu sağlamak amaçlanmaktadır (17). Günümüzde YGG tümör tedavisinde operasyon sonrası RT ve TMZ KT si standart tedavi olmakla beraber bu yöntemle de KRT başlanana kadar geçen sürede tümör kavitesine sitotoksik ajan uygulanmış olabilir. McGirt et al. (18) yaptığı çalışmada Giadel ve standart tedavi kombinasyonu uygulanan 33 hastada ortanca sağkalım 20.7 ay, iki yıllık sağkalım ise \%36 oranında bulunmuştur. Benzer şekilde Miglierini et al. (17) yaptığı geriye dönük çalışmanın sonuçlarıda bu sağkalım avantajını desteklemektedir. Bu çalışmalar ışığında daha fazla ileriye yönelik çalışma yapılarak standart olarak uygulanması yönünde umut verici sonuçlar elde edilebilir. Bizim çalışmamızda da operasyon ile RT arasındaki süre ortanca 31 gün olup sağkalım ile ilişkisi gösterilememiştir.

Sonuç olarak; YGG tümörler her türlü tedaviye rağmen kötü seyretmekte, maksimum güvenli cerrahi rezeksiyon sonrası RT ve KT ile tedavinin devam ettirilmesi anlamlı sağkalım avantajı sağlamaktadır. YGG tümörlü hastalarda genel sağkalım ve prognozla ilişkili faktörler açısından sonuçlarımız literatürle uyumlu bulunmuştur.

Çıkar Çatışması: Çalışmada herhangi bir çıkar çatışması yoktur.

Finansal Çıkar Çatışması: Çalışmada herhangi bir finansal çıkar çatışması yoktur.

Yazışma Adresi: Meryem Aktan,

Adres: Necmettin Erbakan Üniversitesi, Meram Tıp Fakültesi, Radyasyon Onkoloji Anabilim Dalı, Meram, Konya

Email: meryemaktan@gmail.com

Tel: + 903322237263 Fax: + 903322236181

\section{KAYNAKLAR}

1. Wen PY, Kesari S. Malignant gliomas in adults. N Engl J Med 2008;359(5):492-507.

2. Louis DN, Ohgaki H, Wiestler OD, et al. The 2007 WHO classificationof tumours of the central nervous system. Acta Neuropathol 2007;114(2):97-109.

3. PolednakAP, Flannery JT. Brain, other central nervoussystem, and eye cancer. Cancer 1995;75(1 Suppl):330-7.

4. Stupp R, Hegi ME, Mason WP, et al. European organization for research and treatment of cancer brain tumour and radiation oncology groups; national cancer institute of Canada clinical trials group. Lancet Oncol 2009;10:459-66.

5. Stupp R, Mason WP, van den Bent MJ, et al. Radiotherapy plus concomitant and adjuvant temozolomide for glioblastoma. $\mathrm{N}$ Engl J Med 2005;352(10):987-96.

6. Nieder C, Astner ST, Grosu AL. Glioblastoma research 20062010: Pattern of citation and systematic review of highly cited articles. Clin Neurol Neurosurg 2012;114(9):1207-10.

7. Curran WJ Jr, Scott CB, Horton J, et al. Recursive partitioning analysis of prognostic factors in three Radiation Therapy Oncology Group malignant glioma trials. J Natl Cancer Inst 1993;85(9):704-10.

8. Würschmidt $F$, Bünemann $\mathrm{H}$, Heilmann HP. Prognostic factors in high-grade malignant glioma. A multivariate analysis of 76 cases with postoperative radiotherapy. Strahlenther Onkol 1995;171(6):315-21.

9. Buckner JC. Factors influencing survival in highgradegliomas. Semin Oncol 2003;30(6 Suppl 19):10-4.

10. Stupp R, Reni M, Gatta G, et al. Anaplastic astrocytoma in adults. Crit Rev Oncol Hematol 2007;63(1):72-80.

11. Casartelli G, Dorcaratto A, Ravetti JL, et al. Survival of high grade glioma patients depends on their age at diagnosis. Cancer Biol Ther 2009;8(18):1719-21.

12. Pang $B C$, Wan $W H$, Lee $C K$, et al. The role of surgery in high-grade glioma-is surgical resection justified? A review of the current knowledge. Ann Acad Med Singapore 2007;36(5):358-63.

13. Sanai N, Berger MS. Operative techniques for gliomas and the value of extent of resection. Neurotherapeutics 2009;6(3):478-86.

14. Arslan $S A$, Güney $Y Y$, Altundağ MD, et al. Yüksek gradlı glial tümörlerde radyoterapi sonuçları ve prognostik faktörler: Ankara Onkoloji Hastanesi'nin beş yıllık deneyimi. Türk Onkoloji Dergisi 2014;29(3):97-103.

15. Laperriere N, Zuraw L, Cairncross G. Cancer care Ontario Practice Guidelines initiative neuro-oncology disease site group. Radiotherapy for newly diagnosed malignant glioma in adults: a systematic review. Radiother Oncol 2002;64(3):25973.

16. Malmström A, Grønberg BH, Marosi C, et al. Temozolomide versus Standard 6-week radiotherapy versus hypofractionated radiotherapy in patients older than 60 years with glioblastoma: the Nordic randomised, phase 3 trial. Lancet Oncol 2012;13(9):916-26.

17. Miglierini $P$, Bouchekoua $M$, Rousseau B, et al. Impact of the per-operatory application of GLIADEL wafers (BCNU, carmustine) in combination with temozolomide and radiotherapy in patients with glioblastoma multiforme: efficacy and toxicity. Clin Neurol Neurosurg 2012;114(9):1222-5.

18. McGirt MJ, Than KD, Weingart JD, et al. Gliadel (BCNU) wafer plus concomitant temozolomide therapy after primary resection of glioblastoma multiforme. J Neurosurg 2009;110(3):583-8. 